\title{
Report of a new case of "genitopatellar" syndrome which challenges the importance of absent patellae as a defining feature
}

\author{
L Armstrong, J T R Clarke
}

J Med Genet 2002;39:933-934

\begin{abstract}
$\mathrm{n}$ a recent paper, Cormier-Daire $e t$ al ${ }^{1}$ proposed a new condition, "genitopatellar syndrome". They highlighted the association of abnormal patellae, genital and renal anomalies, dysmorphic features, and mental retardation in seven children (including two sets of sibs), and in a child previously reported by Goldblatt et al. ${ }^{2}$ They suggested probable autosomal recessive inheritance and attributed the observed predominance of males among reported patients to the easier recognition of genital abnormalities in males.
\end{abstract}

\section{CASE REPORT}

We report a 3 month old male patient who was born to non-consanguineous parents. His adult father functions intellectually at approximately the grade 3 level; the aetiology of his learning difficulties is not known and he had no congenital anomalies. One of the patient's paternal half brothers is autistic. Other sibs and half sibs are healthy. There were no known teratogenic exposures. At the 20 week prenatal ultrasound, hydronephrosis was noted, and at 25 weeks' gestation renal cysts were shown sonographically.

The boy was delivered at term with a weight of $3395 \mathrm{~g}$ (45th-50th centile) and a head circumference of $33 \mathrm{~cm}$ (15th20th centile). Initially his respiratory efforts were poor and he had apnoeic and bradycardic episodes. He was an irritable baby who arched. He had an unusual cry, central hypotonia and peripheral hypertonia, and pale optic nerves. His face was coarse, there was a glabellar haemangioma, and microretrognathia. The nose had a prominent root, a bulbous tip, and downward facing nares. The tragi of the ears were small, the antitragi were prominent, and the lobes were attenuated. The palate was high arched, the skin was soft and somewhat redundant, and tracheal indrawing suggested tissue laxity. There were palpable breast tissues, single palmar creases, bilateral flexion contractures in the lower extremities (the hips were $5-10^{\circ}$ short of full extension, the knees did not extend beyond $90^{\circ}$ ), reducible varus clubbed feet, and a hypoplastic empty scrotum. He had dimples on the lateral and medial anterior aspects of his knees and we were unable to palpate patellae. Investigations showed periventricular neuronal heterotopia, agenesis of the corpus callosum, congenital heart disease (atrial and ventricular septal defects, patent ductus arteriosus, and dilated aortic arch), dislocated patellae of normal size, and a multicystic kidney on the left and a hydronephrotic kidney on the right. Skeletal survey showed a pair of small cervical ribs with 11 pairs of thoracic ribs, and a mild thoracolumbar scoliosis, possibly positional. A relative shortening of the long bones of the lower extremities was queried. No note of pelvic bone hypoplasia was made, the hip joints were aligned, and the phalanges were normal lengths. $G$ banded chromosomes at the 500 band level of resolution, prepared from a blood sample, showed a normal male karyotype.

Our patient's head grew slowly over his first month so that at 1 month of age the OFC was $34.2 \mathrm{~cm}$ (2nd centile). He has

\section{Key points}

- Cormier-Daire et al' recently highlighted the association of mental retardation, dysmorphic features, genital and renal anomalies, and abnormal patellae. They proposed a new, probably autosomal recessive, "genitopatellar syndrome".

- We describe a probable case, with features that would extend the syndrome phenotype.

- He is a 3 month old male patient who was born to nonconsanguineous parents. He has an abnormal neurological examination, microcephaly, agenesis of the corpus callosum, and neuronal heterotopia. He has dysmorphic features, congenital heart disease, 11 thoracic ribs, cryptorchidism, scrotal hypoplasia, ureterohydronephrosis, and a multicystic kidney. His legs are relatively short, there are flexion contractures of the knees, and bilateral clubbed feet. The extensor surfaces of the knees are dimpled and the patellae are not palpable, but dislocated patellae were seen on ultrasound.

remained in hospital care since birth because of oxygen requirements and difficulties with establishment of feeds and management of nephrostomy tubes.

\section{DISCUSSION}

The concurrence of agenesis of the corpus callosum and multiple renal cysts led us to consider Meckel-Gruber, Zellweger, Fryns, and glutaric aciduria type 2 syndromes. However, our patient does not have the encephalocele, hepatic lesions, or polydactyly common in Meckel-Gruber syndrome. He does not have the facial appearance, liver abnormalities, epiphyseal stippling, or raised concentrations of plasma very long chain fatty acids seen in Zellweger syndrome. He does not have a diaphragmatic hernia, a cardinal feature of Fryns syndrome. Finally, he does not have the metabolic disturbances typical of glutaric aciduria type 2 syndrome.

Many of our patient's features are similar to those of the eight cases discussed as "genitopatellar syndrome" by Cormier-Daire et al (table 1). We think our patient shares this diagnosis despite the fact that he has grey matter heterotopia and congenital heart disease, which have not been previously described, and that he does not share the skeletal differences noted in some of the previous patients (table 1).

Absence of the patella is listed by Cormier-Daire et al $^{1}$ as a defining feature of the genitopatellar syndrome and is emphasised in the syndrome name. We clinically suspected absence of the patellae in our patient because he had dimples on the lateral and medial anterior aspects of his knees and we 
Table 1 Features of our patient are similar to those of previously reported patients

\begin{tabular}{|c|c|c|c|c|c|c|c|c|c|}
\hline & \multirow[b]{2}{*}{ Present case } & \multirow[b]{2}{*}{ Goldblatt et ap } & \multicolumn{7}{|c|}{ Cormier-Daire et $a l^{\prime}$} \\
\hline & & & 1 & 2 & 3 & 4 & 5 & 6 & 7 \\
\hline Microcephaly & + & + & + & + & + & + & + & + & + \\
\hline Agenesis of corpus callosum & + & & + & + & - & + & $?$ & - & + \\
\hline Heterotopia & + & & & & & & & & \\
\hline Hypotonia & Central & & + & + & + & & + & + & \\
\hline \multicolumn{10}{|l|}{ Dysmorphic features } \\
\hline Coarse face & + & + & + & + & + & + & + & + & + \\
\hline Broad/large nose & + & + & + & + & + & + & + & + & + \\
\hline Micrognathia & + & + & - & + & - & + & + & - & + \\
\hline $\begin{array}{l}\text { Lung disease or respiratory } \\
\text { difficulties }\end{array}$ & + & & + & + & - & + & + & - & + \\
\hline Laryngomalacia & + & & + & & & & & & \\
\hline \multicolumn{10}{|l|}{ Flexion deformities } \\
\hline Hips & + & & + & + & + & + & + & + & + \\
\hline Knees & + & + & + & + & + & + & + & + & + \\
\hline Club feet & + & & + & + & + & + & + & + & + \\
\hline \multicolumn{10}{|l|}{ Skeletal survey } \\
\hline Brachydactyly & - & & & + & + & & & + & \\
\hline Hip dislocation & - & + & + & + & + & & & + & \\
\hline Pelvic hypoplasia & - & & + & + & + & & & + & \\
\hline Other & $\begin{array}{l}\text { ?Scoliosis, ?relative } \\
\text { shortness of long bones of } \\
\text { legs }\end{array}$ & $\begin{array}{l}\text { Osteoporosis, radial head } \\
\text { deformity, scoliosis, coxa } \\
\text { vara }\end{array}$ & & & & & & & \\
\hline Renal anomalies & UHC MC & Ectopic, dysplastic & $\mathrm{HN}$ & $\mathrm{HN} M C$ & $\mathrm{HN}$ & $\begin{array}{l}\text { UHN } \\
\text { MC }\end{array}$ & $\mathrm{HN}$ & UHN & $\mathrm{HN} M C$ \\
\hline \multicolumn{10}{|l|}{ Genital anomalies } \\
\hline Clitoral hypertrophy & & & + & & & & & & \\
\hline Scrotal hypoplasia & + & + & & + & + & + & + & + & + \\
\hline Cryptorchidism & + & + & & + & + & + & + & + & + \\
\hline Karyotype & $46, X Y$ & $46, X Y$ & $46, X X$ & $46, X Y$ & $46, X Y$ & $46, X Y$ & $46, X Y$ & $46, X Y$ & $46, X Y$ \\
\hline Patellae & csa, ns, d & $r, d$ & $a$ & $\operatorname{csa}$ & $a$ & $\operatorname{csa}$ & $\operatorname{csa}$ & $a$ & $\operatorname{csa}$ \\
\hline
\end{tabular}

could not palpate patellae. However, an ultrasound study showed our patient's patellae to be laterally dislocated, but of normal size. The patient of Goldblatt $e t$ al $^{2}$ was described as having barely palpable, rudimentary, dislocated patellae. Some of the patients in the series of Cormier-Daire et al were reported to have absent patellae on clinical suspicion because of dimples similar to those seen in our patient. As Goldblatt et $a l^{2}$ observed, absent patellae have been associated with multiple joint contracture syndromes. This invites speculation that maldevelopment of the patellae might in some cases be secondary to intrauterine knee contractures. We suggest that if the patients summarised in table 1 in fact share a common syndrome, the flexion deformities might be the primary knee problem, and thus would be a more direct syndrome criterion than absence of the patellae.

\section{Authors' affiliations}

L Armstrong, Department of Medical Genetics, Children's Hospital of Eastern Ontario, Ottawa, Ontario, Canada

J T R Clarke, Division of Clinical and Metabolic Genetics, Hospital for Sick Children and University of Toronto, Toronto, Ontario, Canada

Correspondence to: Dr L Armstrong, Department of Medical Genetics, Children's Hospital of Eastern Ontario, 401 Smyth Road, Ottawa, Ontario, Canada K1H 8L1; liarmstrong@cheo.on.ca

\section{REFERENCES}

1 Cormier-Daire V, Chauvet ML, Lyonnet S, Briard ML, Munnich A, Le Merrer M. Genitopatellar syndrome: a new condition comprising absent patellae, scrotal hypoplasia, renal anomalies, facial dysmorphism, and mental retardation. J Med Genet 2000;37:520-4.

2 Goldblatt J, Wallis C, Zieff S. A syndrome of hypoplastic patellae, mental retardation, skeletal and genitourinary anomalies with normal chromosomes. Dysmorphol Clin Genet 1988;2:91-3. 